\title{
From the Desk of the Editor
}

Volume 85 No.1\&2, January-June, 2015 issue of the Journal of the Association of Engineers, India is being published just before the Annual General Body meeting of the Association of Engineers, India.

In this issue also, as usual, there is a column of the President of the Association, Prof. Dr. Madhusudan Bhattacharyya. He goes on narrating briefly the glimpse of his long standing experience in industry and in academics. One can generate idea about intricacies of industrial consultancy from his column. He also expresses valuable opinion on the current state of affairs around us.

Papers included in this issue are related to Mechanical Engineering, Electrical Engineering, Management, etc. A Book Review is also included in this issue.

The contents of the journal is being circulated through Social Networking sites such as Facebook and Linkedin. Researchgate may be used by authors for circulating their papers. We plan to spread the journal articles through on-line system, and the talk is on to implement the same shortly.

The new website of the Association is launched with the address, www.aeindia.org.in, and it is being augmented with new features.

Hope, readers will find this issue interesting. I personally thank paper authors for submitting articles to this journal. Honorable reviewers have done a great job by refereeing each article submitted to this journal. Comments and discussion on the published articles are invited from readers in the form of 'Letter to the Editor' to publish in the journal.

Contents of Vol.84 No.1-4 2014 are included at the end of the issue as a ready reference. The 'Association News' continues to include brief reports of different activities of the Association as a Regular Section. Sad demise of few members is mentioned, along with the untimely death of Er. Asoke Kumar Aich, the Assistant Secretary of the Association.

The newly prepared Membership Form is included within this section so that an interested person can become a member of the Association. An organization can also opt for its Institutional membership.

Articles prepared following Author Guideline are invited for consideration for publication in the Journal of the Association of Engineers, India.

Good quality papers in varying engineering and management areas presented in a conference may also be published in this journal after appropriate extension and revision through the process of peer review. Conference organizers may please contact the Editor in this regard. Detail of the Author Guideline, Declaration Form, Subscription Form and Advertisement Contract Form are available in the Association website, www.aeindia.org.in.

Wish you all the Season's Greetings !

May 12, 2015

Prof. Dr. Santanu Das

The Editor 